\title{
Do Orthodontic Bracket Designs Affect Streptococcus Mutans Count With Herbal Toothpastes?
}

\author{
${ }^{1}$ Aseem Sharma, ${ }^{2}$ Reena Ranjit Kumar, ${ }^{3}$ Akshay Gupta, \\ ${ }^{4}$ Stanley Mathew, ${ }^{5}$ Deepak Phor \\ ${ }^{1}$ Senior Lecturer at Institute of Dental Sciences Jammu \\ ${ }^{2}$ Professor and head at DJ Dental College Modinagar \\ ${ }^{3}$ Professor and head Indira Gandhi Government Dental College Jammu \\ ${ }^{4}$ Private consultant orthodontist \\ ${ }^{5}$ Post graduate student
}

\section{Introduction}

The orthodontist as the clinician is continuously challenged to curb and eliminate White Spot Lesions (WSL) in their patients during orthodontic treatment due to alterations in the oral flora and plaque accumulation leading to enamel decalcification. Orthodontic patients are faced with the hazard of increased retention of food particles and plaque accumulation due to the presence of multiple attachments like brackets and other auxiliaries in the oral cavity forming encatchment areas for plaque.A number of controlled clinical trials have demonstrated that tooth brushing with herbal dentifrices reduces supragingival plaque and gingivitis. Streptococcus mutans is a potent initiator of caries because there are a variety of virulence factors unique to the bacterium and play an important role in caries initiation. Metallic orthodontic brackets have been found to induce specific changes in the oral environment such as reduced levels of $\mathrm{pH}$, increased plaque accumulation, and elevated $\mathrm{S}$. mutans colonization. This study ascertained, if design differences created differences in microbiological counts of the organism being investigated.

\section{Aim and Objective}

To ascertain if herbal dentifrices and different bracket design combination could be effective in reducing $\mathrm{S}$. mutans count in patients undergoing orthodontic treatment.

\section{Materials And Methods}

$>30$ Orthodontic patients were included in the study with SS bracket bonded on tooth number 15 and SLB on tooth number 25 .

$>$ The patients were examined at the first visit as baseline record, after $24 \mathrm{hrs}$ and then after 6 days for comparison. Pooled plaque samples were collected from buccal surface of both teeth and sent for culture.
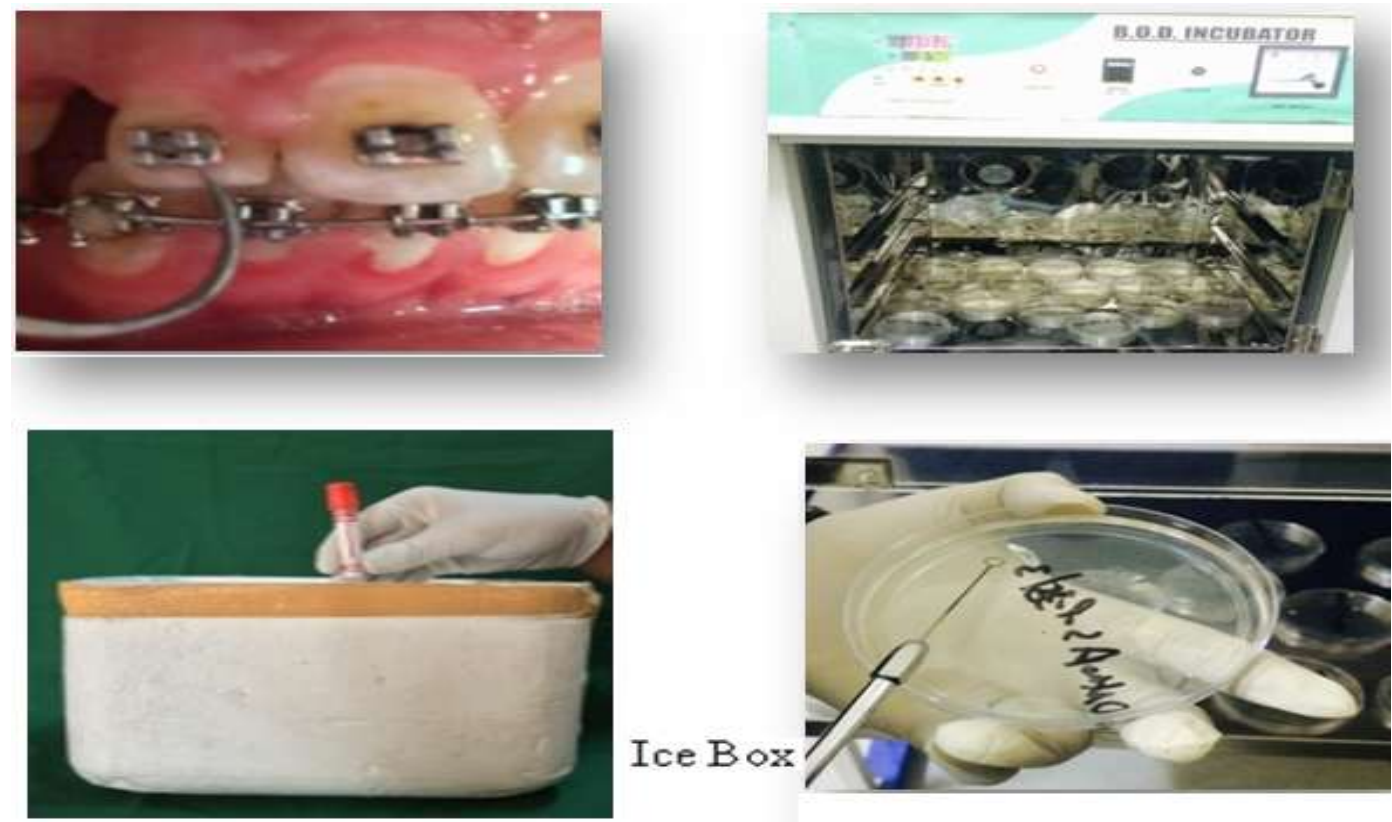


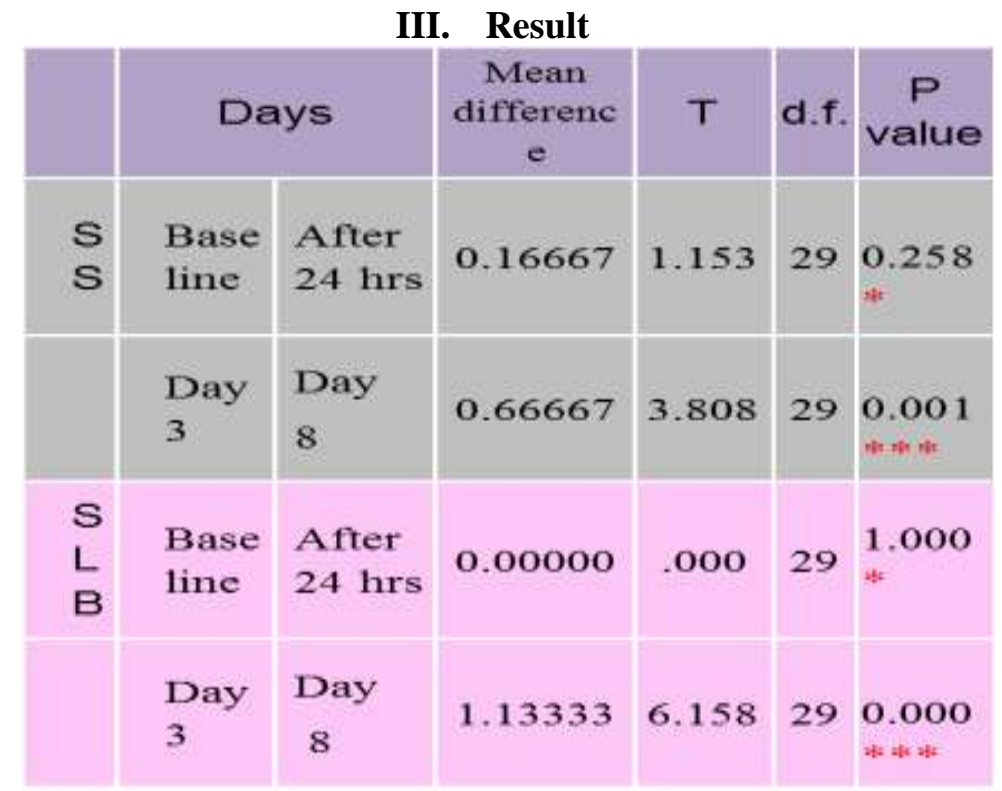

SLB bracket when used with herbal toothpastes showed more reduction of S. mutans ( \pm 1.03333 with $p$ value of $0.000)$ as compared to SS bracket $( \pm 0.83333$ with $\mathrm{p}$ value of 0.000$)$ but no statistically significant difference ( $\mathrm{p}$ $>0.05$ ) was noted between both the brackets.

\section{Conclusion}

- Herbal toothpaste performed well and clinically efficient in reducing S. mutans colony counts around statinless steel and self ligating brackets.

- This would be an useful innovation specially in patients who are periodontally compromised and those who have difficulty in maintaining oral hygiene during orthodontic treatment.

\section{References}

[1] Rosenbloom RG. Salivary Smutans levels in patients before, during \& after orthodontic treatment. Am JOrthod Dentofacial Orthop.1991; 100(1):35-7.

[2] Sukontapatipark W, Agroudi MA. Bacterial colonization associated with fixed orthodontic appliances.Eur J Orthod. 2001 Oct; 23(5):475-84.

[3] Patricia A1, Fernando AM. A Comparative study of invitro antibacterial activity of neem and Meswak extracts against isolated cariogens from dental caries patients. J. Chem. Pharm. Res., 2004, 3(5):638-645

[4] Golpar R, Faranak M, Ehsan K. Chitosan-based polyherbal toothpaste: As novel oral hygiene product. Indian J Dent Res 2010; 21(3): 380-384.

[5] Nitin CM, Adhikrao VY. Polyherbal toothpaste: Oral hygiene product. Indian J Dent Res 2010; 21:380-4

[6] Meyers AI, McQueen MJ.Antimicrobial Efficacy of Different Toothpastes .Saudi Dent J. 2010; 24(5): 83-98.

[7] Jurela A, DarioRD, Pejda S et al. The effect of two different bracket types on the salivary levels of S mutans and S sobrinus in the early phase of orthodontic treatment Angle Orthod.2013; 83(1)140-145.

[8] Sharma A, Sankhla B, Parkar SM, Hongal S et al. Effect of traditionally used neem and babool chewing stick on Smutans. J Clin Diag Res 2014; 20:71-79.

[9] Fadia D, Vandekar M, Vaid N, Vassess D.Plaque accumulation and Streptococcusmutanslevels around self-ligating bracket clips and elastomeric modules: A randomized controlled trial. APOS Trends Orthod. 2015; 5:97-102. 